\title{
ATUAÇÃO DO FARMACÊUTICO NA PREVENÇÃO E ORIENTAÇÃO NO TRATAMENTO DA SÍFILIS CONGÊNITA
}

\author{
Gabrielle Ramos Martins ${ }^{1}$ \\ Leonardo Guimarães de Andrade ${ }^{2}$
}

RESUMO: A sífilis é uma doença infecciosa causada pelo Treponema pallidum com alta taxa de transmissão Vertical, até 10o\%, dependendo da doença materna e do estágio da gravidez. Diagnóstico de sífilis durante a gravidez é simples e deve ser rastreado durante o pré-natal. Mesmo assim, a prevalência dessa patologia ainda é elevada, afetando 2 milhões de gestantes em todo o mundo. Procedimentos para recémnascidos com sífilis congênita, o custo do representante é três vezes maior do que o atendimento prestado ao lactente que não tem essa infecção. $O$ trabalho é uma revisão de literatura que refere-se apresentar a sífilis e seus diferenciados gêneros, possuindo como enfoque básico a sífilis congênita e da maneira como o farmacêutico é capaz de atuar na melhoria à saúde, diagnóstico e utilização exato do medicamento. De um modo geral, o tratamento é com a penicilina, e deve ser estendido aos parceiros sexuais. Não tratar ou tratar indevidamente a sífilis congênita pode causar aborto espontâneo, parto prematuro, complicações agudas e outras sequelas fetais.

Palavras- chave: Sífilis. Gravidez. Doença.

ABSTRACT: Syphilis is an infectious disease caused by Treponema pallidum with a high rate of vertical transmission, up to Ioo\%, depending on the maternal disease and stage of pregnancy. Diagnosis of syphilis during pregnancy is simple and must be tracked during prenatal care. Even so, the prevalence of this pathology is still high, affecting 2 million pregnant women worldwide. Procedures for newborns with congenital syphilis, the cost of the representative is three times higher than the care provided to the infant who does not have this infection. The work is a literature review that refers to presenting syphilis and its different genders, having as its basic focus the congenital syphilis and how the pharmacist is able to act in the improvement

'Graduanda do curso de Farmácia da UNIG- Universidade Iguaçu. E-mail: gabrielleramosm@gmail.com

${ }^{2}$ Cirurgião Dentista e enfermeiro. Professor da Universidade Iguaçu. E-mail: leonard.gui@homail.com. 
of health, diagnosis and exact use of the medicine. In general, treatment is with penicillin, and should be extended to sexual partners. Failure to treat or improperly treat congenital syphilis can cause miscarriage, premature birth, acute complications and other fetal sequelae.

Keywords: Syphilis. Pregnancy. Disease.

\section{INTRODUÇÃO}

A sífilis é geralmente caracterizada por suas manifestações clínicas em um ano, incluindo o primeiro, segundo e casos recentes de sífilis latente. Outra categoria é a sífilis tardia, que aparece após um período de tempo a um ano da infecção, incluindo sífilis latente tardia e sífilis terciária (AVEELLEIRA, 2006). De acordo com sua via de transmissão, ela pode ser dividida em: sífilis adquirida, gestacional e congênitas (BRASIL, 2010).

De um modo geral, a sífilis é transmitida através do contato sexual desprotegido, e por contato com úlceras. (AVELLEIRA, 2006). Embora existam tratamentos no mercado, os indivíduos têm oportunidades e a taxa de reinfecção é duplicada (DORADO et al., 2014). Este contágio é devido a falta de compreensão e familiaridade com a doença, subnotificação, por agentes de saúde que precisam de educação permanente (LAFETÁ, 2oi6).

Com a DESIÇÃO DORADO (2014), a partir do momento da infecção, o desenvolvimento da sífilis primária é caracterizado pela presença de úlceras (sinais da multiplicação das bactérias). Por outro lado, as manifestações secundárias são as lesões cutâneas do tronco e das extremidades do corpo, exceto lesões mucosas, febre, fraqueza muscular, queda de cabelo, madarose e outras (DORADO et al., 2014). A terceira (fase tardia) pode se manifestar vários anos após a infecção e é caracterizada por pele, rim, osso, fígado, etc. (ALMEIDA, 2014). A sífilis congênita acontece no momento em q o Treponema pallidum é conduzido para uma criança durante a gravidez (DORADO., 2016). 
A sífilis pode ser diagnosticada por meio direto, que comprovam as bactérias ou indiretamente que reconhecem anticorpos na infecção (DORADO et al., 2006). 2014). Dorado et al. (2014) afirma que o teste mais comumente usados é o teste indireto: VDRL (de Inglês, Laboratório de Pesquisa STD e RPR (plasma rápido Reagin), barato e rápido.

A droga de preferência para o cuidado da doença é a penicilina, pois pode tratar a mãe e o feto. O remédio é barato e fácil de administrar. Se o paciente é alérgico à penicilina, existem outros medicamentos à sua escolha, entre os quais podemos referir a doxiciclina, azitromicina e tetraciclina (SILVA, 2016).

Nesse caso, o farmacêutico desempenha um papel importante no tratamento da sífilis, pois pode orientar o uso correto dos medicamentos. Outra tarefa é acompanhar os pacientes para ver se há algum problema durante a medicação (OMS, 2006)

\section{OBJETIVOS}

\section{I.I Objetivo Geral}

O trabalho é uma revisão de literatura que refere-se apresentar a sífilis e seus diferenciados gêneros, possuindo como enfoque básico a sífilis congênita e da maneira como o farmacêutico é capaz de atuar na melhoria à saúde, diagnóstico e utilização exato do medicamento.

\subsection{Objetivos específicos}

- Examinar os atos da sífilis e em especial a sífilis congênita;

- Analisar sua transmissão;

- Entender quais são os testes usados para reconhecer o agente responsável;

- Entender o tratamento de definição para a luta ao T. pallidum;

- De que modo se prevenir através à essa doença. 
- Entender como o farmacêutico opera na atenção farmacêutica dos diferentes gêneros da sífilis.

\section{JUSTIFICATIVA}

A ideia do tema faz sentido e precisa informar a todos a importância do diagnóstico precoce da sífilis em gestantes a fim de buscar medidas preventivas para evitar a transmissão da mãe para o feto. Portanto, o trabalho atual contribuirá para informação científica sobre medidas de prevenção da sífilis.

\section{METODOLOGIA}

Foi realizada uma emenda bibliográfica sobre o assunto da sífilis e atenção farmacêutica, na qual dirigiram-se pesquisas em artigos científicos, empregando conhecimento de referência ao Google Acadêmico, revistas e jornais onlines, Scientific Eletronic Library Online (SciELO), site do Ministério da Saúde, Conselho Federal de Farmácia, Biblioteca Virtual em Saúde do Ministério da Saúde.

Foram aplicadas as palavras chaves: Treponema pallidum, Sífilis, Atenção Farmacêutica. A emenda bibliográfica abrangeu buscas em livros, dissertações, artigos de revisão e modelos que trouxeram uma primeira leitura para análise de seu assunto, tornando-se eleitos tais que mostraram superior à sua importância sobre a intenção do presente trabalho.

\section{TRANSMISSÃO}

“A sífilis é uma doença sexualmente transmissível por via sexual (sífilis adquirida) e verticalmente (sífilis congênita) transmissão vertical da placenta da mãe ao feto”. Outras formas raras de transmissão de menos interesse epidemiológico são indiretos. (AVALLEIRA; BOTTINO,2006).

Objetivos contaminados são por, tatuagens e transfusões de sangue. Segundo os autores, o risco de contágio varia de $10 \%$ a $60 \%$. 


\section{I Manifestações}

"A história natural da doença mostra evolução que alterna períodos de atividade com características clínicas, imunológicas e histopatológicas distintas (sífilis primária, secundária e terciária) e períodos de latência (sífilis latente)" ((AVELLEIRA; BOTTINO, 2006; pir).

A sífilis é subdividida em sífilis recente, se o diagnóstico for em até um ano após a infeção, é sífilis tardia, quando for feito um ano depois o diagnóstico.

\section{- PRIMÁRIA}

A sífilis primária acontece devido à existência de Treponema pallidum em contato com organismo humano. Em relação às manifestações clínicas, o indivíduo apresenta lesões ulcerosas, indolor, com fundo endurecido e bordas chamadas úlceras duras (SOROA et al., 2017; SARKISIAN; BRILLHART, 2018). A infecção tem um período de incubação de 3 a 90 dias (ALMEIDA, 2014; DORADO et al., 2014). As úlceras (que é uma manifestação da reprodução bacteriana) aparecem em até 21 dias após a vacinação, pode ser no pênis (Figura I), vagina ou fora dos órgãos genitais (ânus, Boca (Figura 2), língua, mama) (SARKISIAN; BRILLHART, 20I8; AVEELLEIRA; Botino, 2006). Algumas dessas bactérias atingem os nódulos linfáticos na área da infecção, e então a doença se espalha pela corrente sanguínea (DORADO et al., 2014).

A lesão tem alta carga bacteriana e tem o poder de contagiar outras pessoas que podem entrar em contato com uma pessoa infectada, e sem tratamento tende a sumir espontaneamente dentro de 28 a 35 dias, sem ficar cicatrizes (AVEELLEIRA; BOTTINO, 2006; ERRANTE, 2016). Pessoas que fazem sexo anal, haverá câncer localizado na região anorretal, que pode ser confundido com uma fissura anal, decorrente de sangramento e dor durante a defecação (DORADO et al., 2014). 
Figura I: Sífilis primária - Esclerocarcinoma precoce de sífilis no pênis

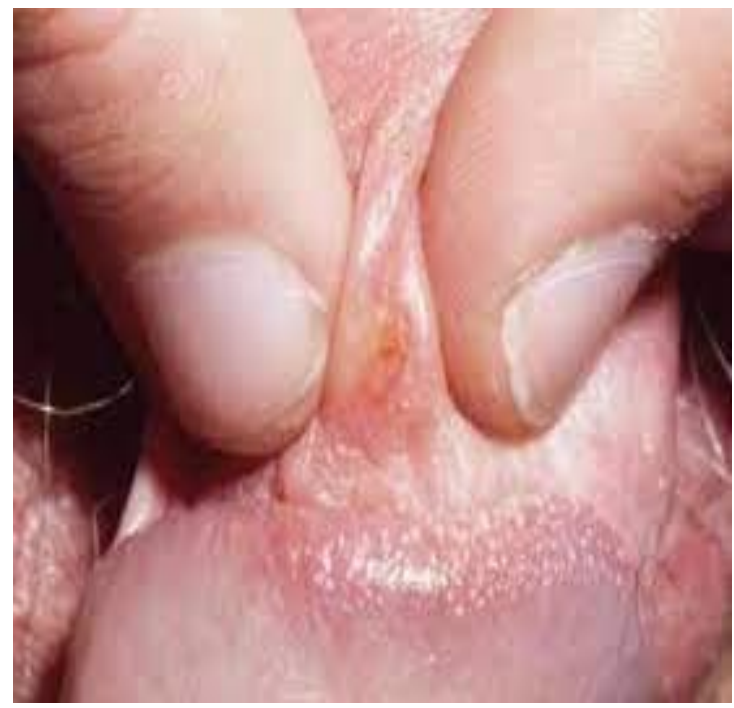

FONTE:_DORADO et al, 2014

Figura 2: Esclerocarcinoma no estágio inicial da sífilis na cavidade oral

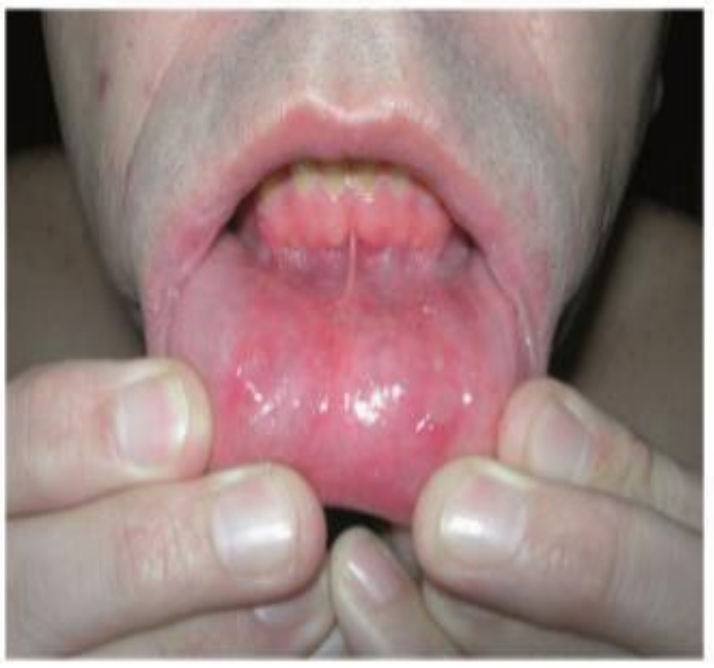

Fonte: DORADO et al, 2014 


\subsection{Sífilis secundária}

A característica da sífilis secundária é que a sífilis se espalha para todos os órgãos que passam pelo sangue e causam alguma série de sintomas por meio de reações do sistema imunológico acionado pelo organismo hospedeiro, afetando pele e órgãos internos (AVEELLEIRA; BOTTINO, 2006; SOROA et al., 2017;). As manifestações clínicas mais globais são: febre, queda de cabelo, dor de cabeça, erupções na pele erupções cutâneas pleomórficas envolvem principalmente o tronco e membros, lesões cutâneas mucosa, hepatoesplenomegalia, glomerulonefrite, dor nas articulações, anorexia, coceira, etc.(AVELLEIRA; Botino, 2006; ERRANTE, 2or6; SOROA et al., 2017). A manifestação mais comum nesta fase são lesões cutâneas, que aparece um grande número, comumente no tronco (Figura 3) e nos membros (palma da mão e planta dos pés) (Figura 4) (DORADO et al., 20I4; ERRANTE, 20I6; SARKISIAN; Brillhart, 2018).

Estas erupções têm $0,5^{-2} \mathrm{~cm}$ de tamanho. Quando a lesão ocorre as áreas úmidas do corpo são sinais de condiloma acuminado plano. Quando afeta a membrana mucosa a boca ou os órgãos genitais são brancos e podem ser divididos em 3 tipos: erosivos, papulosos ou Úlceras (DORADO et al., 2014).

Figura 3: Lesões cutâneas no tronco no estágio secundário da sífilis

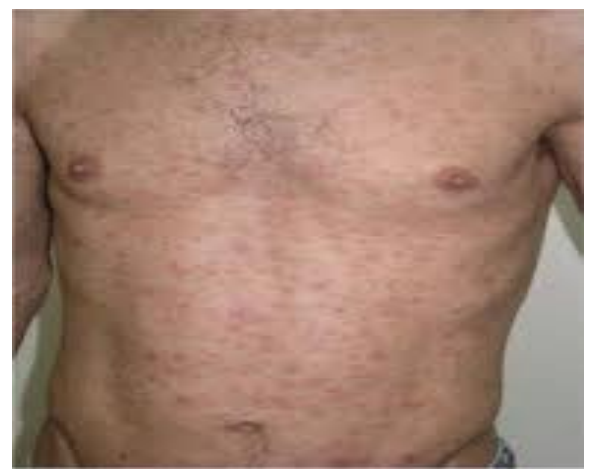

Fonte: DORADO et al., 2014 
Figura 4: Lesões cutâneas na planta das mãos no estágio secundário da sífilis

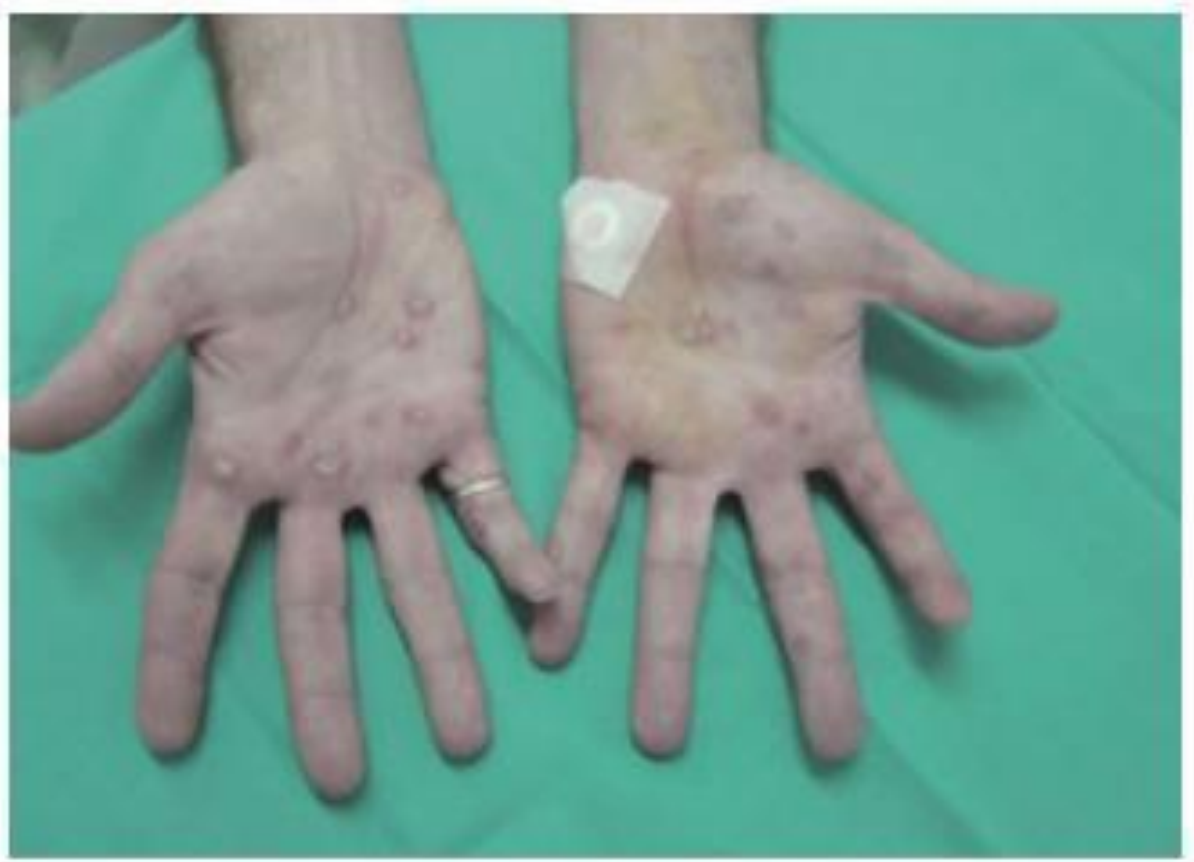

Fonte: DORADO et al., 2014.

\subsection{Terciária}

A sífilis terciária é capaz de ocorrer dentro de I a io anos após o contágio (ERRANTE, 20I6). Apenas um terço das pessoas infectadas desenvolverá a sífilis até este estágio, são aqueles que não são tratados adequadamente (ERRANTE, 2016; GUIMARÃES et al., 2017). Na maioria dos casos, durante este estágio, observamos quase nenhum número total de espiroquetas (AVEELLEIRA; BOTTINO, 2006; ERRANTE, 2016). As manifestações clínicas nesta fase são lesões gelatinosas na pele (Figura 5), membranas mucosas e ossos (AVELLEIRA; Botino, 2006; ERRANTE, 2016). Essas lesões afetarão o sistema cardiovascular e nervoso, bem como músculo e fígado (AVEELLEIRA; Botino, 2006; SOROA et al., 2017). Intitulamos que essas lesões de gomas de sífilis, eles são nodulares e indolores, e podem facilmente formar úlceras e cicatrizes (DORADO et al., 2014; SOROA et al., 2017). 
Figura 5: Goma sifilítica na pele em estágio terciário

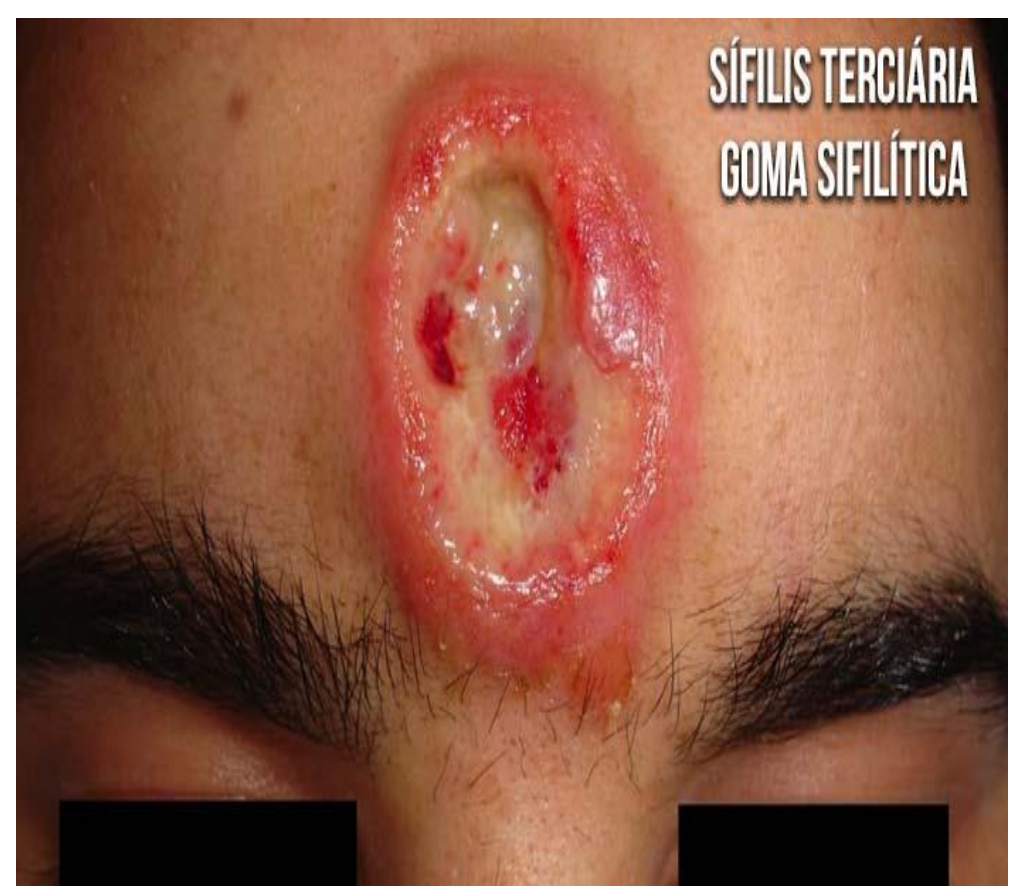

Fonte: 〈Fotos sífilis precoce e avançada [imagens fortes] - MD.Saúde (mdsaude.com)〉

\subsection{SÍFILIS LATENTE}

Não há sintomas ou sinais de infecção nesta fase, apenas através de teste sorológico em pacientes com sintomas de sífilis primária e secundária. Depois que esses dois sintomas desaparecerem espontaneamente, o período de incubação começa. Isso pode ser tardio mais de um ano após a infecção ou precoce em menos de um ano. (DORADO et al, 2or4; HENAO-MARTINEZ, JOHNSON, 2014).

\section{CLASSIFICAÇÃO DA SÍFILIS}

\subsection{Congênita}

“No território brasileiro a sífilis congênita foi classificada como uma doença de notificação compulsória, a partir de 22 de dezembro de 1986, com a publicação da portaria do Ministério da Saúde número 542" (BRASIL, 1986). Sífilis congênita ocorre 
quando o Treponema pallidum é espalhado por todo o corpo para uma criança quando a mãe não está recebendo tratamento, o tratamento é impróprio, por reinfecção; através da placenta ou no momento do parto. O contágio pode causar aborto, nascimento prematuro, perda fetal e falecimento perinatal (ERRANTE, 2016; VASCONCELOS, etc.) et al., 2016; MACÊEO et al., 2017).

Há maior chance de transmissão para o feto na fase em que existe um grande número de bactérias circulando no sangue, ou seja, na fase aguda. Na sífilis primária e secundária, a taxa está entre 70-100\%. Já na latente recente, atingiu 40\% e o período de incubação atingiu 1o\%.

Crianças menores de dois anos com diagnóstico de sífilis, temos sífilis congênita precoce, seus aspectos clínicos são: parto prematuro, osteocondrose, anemia, Hepatoesplenomegalia, alterações do sistema nervoso central, baixo peso, nariz em sela, icterícia, lesões cutâneas e mucosas, febre, rinite, trombocitopenia, meningite, pele pálida outros sintomas (SARACENI 2005; ERRANTE, 2016;). Se caso o diagnóstico for crianças com mais de dois anos, temos sífilis congênita tardia e suas qualidades clínica é irreversível, entre as quais podemos citar: a tíbia em forma de lâmina, queixo curto, surdez, testa olímpica, dentes de Hutchinson, ceratite intersticial, Molares de Blackberry, surdez causada por danos nos nervos entre outros sintomas (Avelleira; Botino,2006; Ministério da Saúde, 2015). Destaca-se que a sífilis congênita afeta os recém-nascidos mais do que qualquer outra enfermidade neonatal (DORADO, 2014).

\section{SÍFILIS EM GESTANTES}

É transmitida da mesma forma que a sífilis adquirida, isto é, através de vias sexuais. $\mathrm{O}$ agravante nesse caso é a infecção da gestante, se não for tratada de forma inadequada, o risco será de contaminação vertical (Milanez Amaral, 2008). O germe 
consegue ser contagiado passando pela placenta em qualquer estágio da gravidez ou pela vagina no decorrer do parto (Milanez; Amaral, 2008).

De acordo com os dados da OMS, o intuito da eliminação da sífilis tem de atingir 95\% de abrangência do pré-natal e tentativas em grávidas, se padronizando, deste modo, a países da América Latina, como Cuba e Chile, em que os índices são de 0,5 casos por 1000 nascidos vivos (KUZNIK et al., 2015))

O Ministério da Saúde recomenda que seja realizado um teste sorológico para VDRL no início do pré-natal (se o resultado for positivo, deve-se tratar a gestante e seu parceiro), e outro teste sorológico para VDRL no terceiro trimestre ( por volta da $28^{\text {a }}$ semana). Além disso, Rastreio de sífilis durante o parto ou aborto (Brasil, 2005a; Ministério da Saúde, 2006; Milanes; Amaral, 2008; Silva, 2016). Com isso tem de a um imenso número de gestantes contagiada pelo Treponema pallidum e à simplicidade de análise e tratamento, pois quanto mais precoce o diagnóstico e o tratamento mais adequados, maior a chance de redução desse número (BRASIL, 2005b; MILANEZ; AMARAL, 2008; Rodriguez; GUIMARÉS, 2004). É necessário compreender que o tratamento apropriado e instantâneo do parceiro e da gestante está relacionado aos medicamentos a serem utilizados e sua duração, visto que a reinfecção é comum nesta doença (Brasil, 20ıо; ERRANTE, 2016).

De acordo com os dados da OMS, o intuito de eliminação da sífilis deve chegar a 95\% da cobertura de pré-natal e testagem para gestantes, o que equivale a países latinoamericanos como Cuba e Chile com taxa de o,5 por I.ooo nascidos existentes (Kuznik Et al. 2015)

\section{ADQUIRIDA}

A sífilis adquirida é uma doença contagiosa sistêmica que se espalha por sexo desprotegido, geralmente por meio dos órgãos genitais ou da área anal. Isto é uma infecção e quase não há nenhum sintoma, o que significa que o indivíduo não tem 
nenhum conhecimento da doença e pode ser transmitido a terceiros. Ela pode se classificar em primário, secundário, terciário e latente (Brasil, 20ıo).

Normalmente há úlceras primárias nos genitais. Afetados, incluindo boca, língua e ânus. Essa patologia já está na segunda a pele, causando úlceras no tronco nos membros e no corpo, como mãos e pés. O terceiro estágio causa sintomas mais graves afeta órgãos internos, sistema cardíaco e até o sistema nervoso central (SNC), isso pode até direcionar à morte. Quanto ao tempo após o contágio, é classificado em latente precoce (menos de um ano) ou incubação tardia (mais de um ano) (BRASIL, 2oIo; HESTON; ARNOLD, 2018).

\section{EPIDEMIOLOGIA}

No Brasil, a incidência em 201 atingiu 3,3 de casos por pessoa I.00o nascidos vivos, a proporção das regiões Nordeste e Sudeste é maior do que outras regiões para ultrapassarem, além disso, há um grande número de casos não relatados, provando que a mortalidade perinatal da sífilis só é encontrada no Espírito Santo, Rio de Janeiro, Santos São Paulo, Paraná, Santa Catarina, Rio Grande do Sul e Mato Grosso Sul, de acordo com indicadores básicos de saúde (BID, 2008) da rede interinstitucional de Informação em Saúde (RIPSA). A maioria da sífilis congênita, os recém-nascidos nascem prematuramente, têm baixo peso ao nascer e precisam ser hospitalizados por um período de tempo. A unidade de terapia intensiva é mais alta, o procedimento para recém-nascidos com sífilis é três vezes maior o custo, e melhor do que o atendimento aos bebês que não apresentam essa infecção.

\section{DIAGNÓSTICO}

Para diagnosticar os portadores da enfermidade, possuímos a técnica direta, que procuram reconhecer a bactéria ou pedaços dela, e o método indireto, que procuram reconhecer soluções dos anticorpos do corpo do hospedeiro ao patogênico (DORADO et $\mathrm{al}, 2014)$. 


\section{Io TÉCNICAS DIRETAS}

Eles comprovam a existência do Treponema pallidum e são considerados indiscutível, pois não sofrem interferência do mecanismo de divisão, ou seja, falsos alarmes. Eles aparecem nos períodos inaugurais da doença, em que existem muitos microrganismos. (AVELLEIRA,2006). Eles são adequados para a primeira e a segunda lesão bolhosas, placas mucosas e condiloma acuminado. Ao usar materiais da mucosa oral, deve-se considerar a possibilidade de ser difícil distinguir Treponema de outras espiroquetas saprofíticas orais, exceto para testes de imunofluorescência direta indiscutível.

\section{MICROSCÓPIO EM CAMPO ESCURO}

O teste envolve verificar a linfa diretamente das lesões. O material é fotografado ao microscópio junto com o condensador de campo escuro, se possível, com luz indireta, visualização de Treponema pallidum e móvel. (AVELLEIRA, 2006). "É considerado um teste rápido, de baixo custo e definitivo. A sensibilidade varia de 74 a $86 \%$, podendo a especificidade alcançar $97 \%$ dependendo da experiência do avaliador”. (AVELLEIRA,2006, p.II7)

\section{IMUNOFLUORESCÊNCIA DIRETA (IFD)}

Um teste altamente específico com uma sensibilidade superior a 90\%. A possibilidade de má interpretação com treponema safruite é quase eliminada. É denominado DFA-TP (detecção direta por anticorpo fluorescente de Treponema pallidum). (AVELLEIRA,2006)

\section{REAÇÃO DA CADEIA DA POLIMERASE}

PCR é uma reação enzimática a qual possibilita repetir milhões de vezes cada sequência de DNA específica. Para isso, é utilizada a enzima DNA polimerase. Ela cópia uma pequena quantidade de DNA, e as cópias são estudadas com diversos fins. (TAMAY DE DIOS et al., 2013). 
A técnica vai amplificar ácidos nucléicos e pode ser usada em amostras frescas. Pode ser feito com poucas amostras, mas as que garantem melhor o resultado é uma amostra retirada de úlceras genitais e lesões exsudativas (Dorado et al., 2014).

\section{TÉCNICAS INDIRETAS}

Por outro lado, as técnicas diagnósticas indiretas são sorológicas, divididas em Treponema e não treponema (DORADO et al., 2014).

A detecção não treponêmica é mais barata, portanto, por razões econômicas e complexidade, eles estão mais dispostos a implementar (Brasil, 2or6; Dorado et al., 2014). Dorado et al. (2014) demonstrou que quando um resultado de reatividade é dado a um teste não treponêmico, um teste treponêmico (mais custoso) é necessário para confirmação, e o exame do treponema será realizado independentemente do estágio da doença e / ou tratamento seja positivo por toda a vida.

As medidas dos padrões usados pela Organização Pan-Americana Saúde (OPAS) e Organização Mundial da Saúde (OMS), Ministério da Saúde (2017). O diagnóstico recomendado é o seguinte:

- No caso de sífilis adquirida, em pessoas com sintomas, é necessário que exista apenas um teste, que pode ser treponema ou não treponema.

- Ao analisar casos de sífilis em mulheres grávidas, existirá uma certa diferença, pois abrange todas as etapas: pré-natal, parto e puerpério.

○ No caso de gestantes assintomáticas, considere apenas um ou dois testes de reatividade sem tratamento prévio de mulheres grávidas.

- Se você é uma mulher grávida com sintomas, você só pode ser definido por meio de testes Treponema, de qualquer título, ou não treponema (MINISTÉRIO DA SAÚDE,2017). 


\section{I5 NÃO TREPONÊMICOS}

Provas não-treponêmicos identificam anticorpos governados para combater antígenos das células rompidas do hospedeiro pelo contágio. Os mais utilizados são o VDRL e o RPR. Os dois contêm particularidade através de 95 a 99\% e empatia entre 85 a 100\% (DORADO et al, 2014).

\section{I6 PROVAS SOROLÓGICAS}

Treponema pallidum no corpo promove a produção de dois tipos de anticorpos: Reactina (Anticorpos IgM e IgG não específicos contra cardiolipina), levando a testes não treponêmicos, e Anticorpos próprios em combate com Treponema pallidum, originados do teste do Treponema. O teste não treponêmico pode ser usado para rastrear a população e monitorar o tratamento, enquanto o teste treponêmico é usado para confirmar o diagnóstico.

\section{VENEREAL DISEASE RESEARCH LABORATORY (VDRL)}

"VDRL é uma reação que acontece entre um antígeno lipídico, em especial a cardiolipina, e o soro do paciente, que leva a formação de flocos, que podem ser vistos ao microscópio óptico (ERRANTE, 2016)”. Compostos antigênicos (lecitina, Colesterol e cardiolipina purificada) se combinam e formam micelas após o contato junto com o anticorpo, essas micelas resultam na formação de flocos visíveis a olho nu, ou sob um microscópio óptico. No entanto, nem todos os anticorpos são da sífilis, isso pode levar a resultados falsos positivos. Portanto, este teste não é determinado apenas para a definição de sífilis (Brasil, 2016).

Durante o primeiro estágio do tratamento da sífilis, o título pode ser negativo, uma vez que o VDRL torna-se positivo dentro de 5 a 6 semanas após a infecção, até três semanas após o início do câncer. No caso da sífilis secundária, temos alta sensibilidade. Nas fases posteriores, o título de anticorpos cai, resultando em sensibilidade baixa. 


\section{I8 RAPID PLASMA REAGIN}

É uma reação entre um antígeno e um anticorpo, mas para a sua visualização é necessária partícula de carbono. RPR é uma variante do VDRL, que tem a melhor estabilidade e fornece o uso de plasma, fornece também uma visão a olho nu (Figura 5) (Brasil, 2016; ERRANTE, 2016).

Figura 5: Resultado não reagente e reagente no Rapid Plasma Reagent

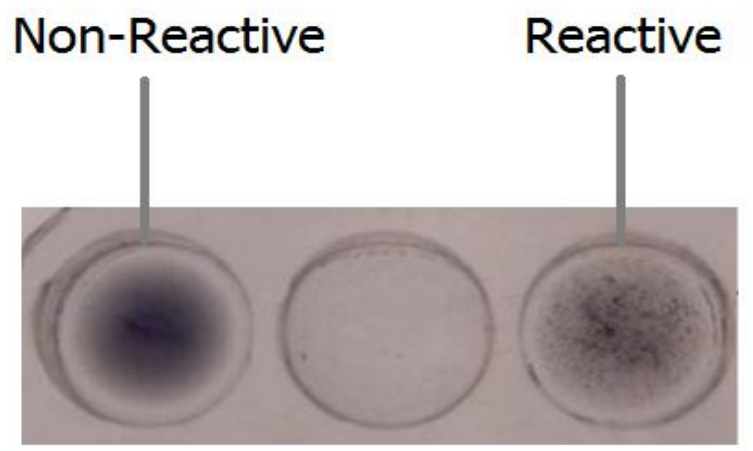

FONTE:_laboratoryinfo.com/rpr, 2017

Estes testes são para monitorar a resposta ao tratamento, porque fornece resultados semiquantitativos no título. Exemplo: "Positivo i:32", em outras palavras, os anticorpos foram detectados no soro diluído 32 vezes. 32 maior título, maior será a atividade da doença. (DORADO et al., 2014).

O resultado durante a encubação pode ser negativo. Resultados falsos positivos foram descritos em mulheres grávidas, pacientes com Lúpus, usadores de drogas injetáveis e tuberculose (DORADO et al., 2014).

\section{TESTES TREPONÊMICOS}

Teste de Treponema pallidum usa Treponema pallidum como um antígeno e usado para confirmar a reatividade do teste não treponêmicos e nos seguintes casos o teste 
não treponêmico quase não tem sensibilidade, como a sífilis tardia. (AVELLEIRA,2006).

Alguns dos testes de treponema mais comumente usados são: Teste de hemaglutinação de treponema Pallidum (TPHA); Encontro de substância de Treponema pallidum (TP-PA); e assimilação de anticorpos treponema fluorescentes (FTA-Abs). Atualmente, a análise de imunoensaio baseado em enzimas (EIA) tem sido usada. A sensibilidade e a especificidade do teste de treponema variam de $90 \%$ a I00\% e de 95\% a I0o\%, nesta ordem (DORADO et al., 2014).

\section{ABSORÇÃO DE ANTICORPOS TREPONÊMICOS FLUORESCENTES}

FTA-Abs é um exame de imunofluorescência a qual requer um microscópio. Fluorescence (Lopez; Estrada, 2005). É feito usando lâminas que contém antígeno Treponema pallidum, da cepa Nichols (originado de Coelho infectado). Eles também têm imunoglobulina anti-humano e isocianato de fluoresceína. Se a amostra contém anti-T. pálido, haverá antígeno se ligando ao anticorpo para formar o primeiro complexo. A Imunoglobulina se junta com compostos e promove cores brilhantes (Brasil, 2016).

Figura 6: Teste de FTA-Abs com efeito positivo

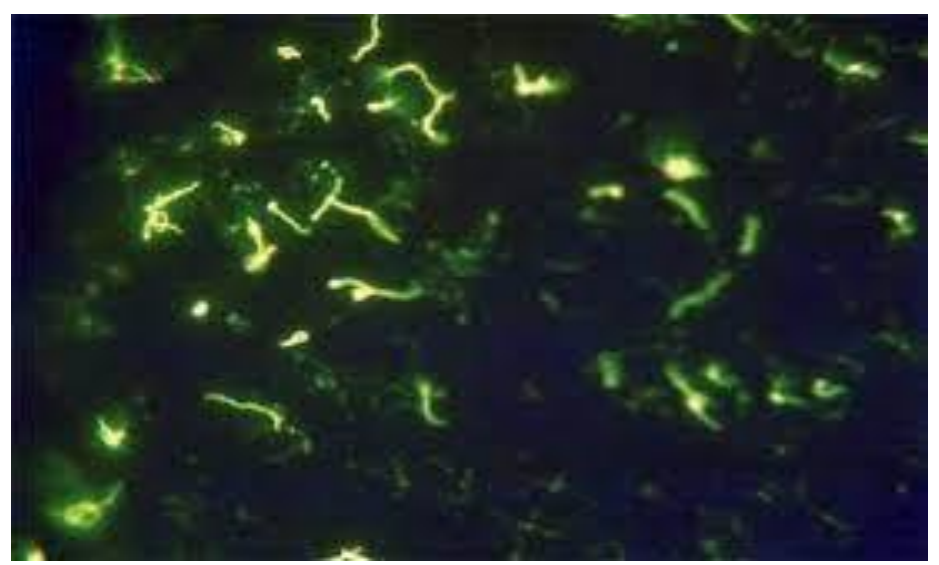

Fonte: https://microbeonline.com/fluorescent-treponemal-antibody-absorption-fta-abs-test/ 

(TPHA)

22. É um exame de hemaglutinação indireta em que o anticorpo treponema liga os glóbulos vermelhos presentes no soro ao antígeno Treponema pallidum (cepa de Nichols), promover a aglutinação de hemácias (Brasil, 20r6).

\section{TRATAMENTO}

Em 1928, o poder bactericida foi descoberto o fungo Penicillium notatus de Fleming que mudaria a história da sífilis e outras doenças contagiosas. A penicilina atua intervindo na associação do peptidoglicano, que é um elemento da parede celular do Treponema pallidum. O resultado é que a água entra no treponema, Em que acaba destruindo. Em 1943, Mahoney provou que a peniclina é eficaz em todas as fases da sífilis. A sensibilidade do efeito do treponema sobre a droga, a velocidade de reação às lesões primárias e secundárias em apenas uma dosagem é uma vantagem que ainda existe até hoje. A penicilina ainda é a droga de escolha, mesmo atualmente não há casos registrados de resistência. (MAHONEY et al., 1943).

A penicilina tem sido usada para tratar por mais de 50 anos a sífilis e sua eficácia foram confirmadas na sífilis adquirida e na sífilis congênita. A penicilina se usar em doses suficientes por um período de tempo é bactericida, não deixar o precursor (formado pela enzima catalítica) da parede celular das bactérias funcionam. A parede não pode mais se reorganizar e está sujeita a ação de hidrólise da lisozima no corpo (GUINSBURG; SANTOS, 2010).

A droga de escolha para o tratamento desta doença é a Penicilina Benzatina, é um medicamento barato e fácil de administrar. O tratamento a seguir é o tratamento com penicilina e deve ser orientado de acordo com o estágio do paciente. No caso da sífilis congênita, a penicilina também é o medicamento de escolha (SILVA, 2016). 
Dorado (2015) também destacou que a penicilina é o remédio mais apropriado para qualquer tipo de sífilis. Mas nos lembra que é preciso identificar com precisão o caso, o tipo de sífilis, porque a infecção e as exibições clínicas serão significativas formas de indicação (penicilina $\mathrm{G}$, procaína, benzatina), dosagem, via de administração e período de cura.

\subsection{Tratamento sífilis precoce (primária, secundária e latente há menos de I ano)}

Adultos: Penicilina G-Benzaptina 2,4 MU, uma única injeção intramuscular. (Damasceno et al,. 2014).

Crianças com mais de um ano: a quantidade de penicilina G-benzaptina é de $50.000 \mathrm{U}$ / kg (máximo de 2,4 MU), também administrado como uma única injeção intramuscular (DORADO et al., 2014, HESTON; ARNOLD, ).

\subsection{Tratamento da sífilis tardia (terciária e latente há mais de I ano)}

Em adultos: realiza-se Penicilina G-benzaptina 2,4 MU foi injetada por via intramuscular uma vez por semana durante 3 semanas (MORALES-MÚNERA et al., 2014; SAMALVIDE-CUBA; BANDA-FLORES, 2010; SOROA et al., 2017). Crianças: A dose de penicilina G-benzaptina deve ser ajustada de acordo com o peso corporal (50.00o U / kg, máximo de 2,4 MU / semana), injeção intramuscular por 3 semanas (HESTON; ARNOLD,2018).

\subsection{Sífilis precoce (primária, secundária e latente precoce)}

I.Doxiciclina roo mg por via bucal duas vezes ao dia por I4 dias (SOROA et al., 2017;).

2. Tetraciclina $500 \mathrm{mg}$ por via oral, 4 vezes ao dia durante 14 dias (DORADO etc. al, 2014; SOROA et al., 2017).

3. Ceftriaxona I g por via intramuscular ou intravenosa, uma vez ao dia Io-I4 dias (DORADO et al., 2014; SOROA et al., 2017). 
4. Azitromicina $2 \mathrm{~g}$, administração oral única (DORADO et al., 2014).

\subsection{Sífilis terciária}

As indicações para sífilis terciária são:

I. Doxiciclina roo $\mathrm{mg}$ por via oral, duas vezes ao dia durante 28 dias (DORADO et al., 2014; SOROA et al., 2017).

2. Tetraciclina $500 \mathrm{mg}$ por via oral, 4 vezes ao dia durante 28 dias (DORADO etc. al, 2014).

3. Ceftriaxona I g por via intramuscular ou intravenosa, uma vez ao dia Io-I4 dias (DORADO et al., 2014)

\subsection{Latente tardia de duração indeterminada}

Nesse caso, as diretrizes são:

I. Ioo $\mathrm{mg}$ de doxiciclina por via oral, duas vezes ao dia por 28 dias (DORADO et al.).

2. Tetraciclina $500 \mathrm{mg}$ por via oral, 4 vezes ao dia durante 28 dias (DORADO etc. Et al., 2014).

\section{Sífilis congênita}

Quando a sífilis congênita da mãe é positiva, o medicamento a escolha é a penicilina benzatina, o tratamento deve terminar 30 dias antes do nascimento do bebê (Ministério da Saúde, 2007; Ministério da Saúde, 2006). No caso de um diagnóstico tardio ou nos seguintes casos se as mulheres grávidas não forem tratadas com eficácia, o Treponema pallidum pode ser transmitido aos bebês (Brasil, 2010). Se o diagnóstico for realizado corretamente e no tempo certo, há chance do contágio não alcançar o feto. Para que isso não aconteça, as gestantes devem receber o tratamento da penicilina no primeiro trimestre da gestação. Se ela está no final da gravidez, a penicilina também 
tratará o feto. Se a mãe é alérgica à penicilina e usar outro tratamento, como a eritromicina, que não tratará infecção fetal porque tem uma ligação transplacentária inesperado e não tem controle (GINSBURG; SANTOS, 2ого).

"Mesmo com ações no período de pré-natal bem realizado, diagnóstico fácil, rápido e eficiente, tratamento medicamentoso de fácil acesso, a sífilis congênita ainda não foi totalmente controlada e persiste como problema de saúde pública. $\mathrm{Na}$ gestação, quando o casal é tratado para a sífilis congênita, há uma grande chance da enfermidade ser minimizada" (HILDEBRAND,2010).

É importante ressaltar que tanto a gestante quanto seu parceiro foram posicionados de forma clara e exata a fim de que as informações possam chegar a eles com precisão. Pessoas de baixa renda e escolaridade pretendem ter mais obstáculos para absorver conhecimento (VASCONCELOS et al., 2016). Vários são os fatores que interferem na adesão do parceiro ao tratamento da sífilis, entre eles podemos citar os socioeconômicos, culturais, educacionais e o próprio tratamento, como medicamentos e via de administração (FIGUEIREDO, 2015). O problema do parceiro insistir no tratamento e apoiar a parceira grávida aumenta muito a chance de completar o tratamento (HILDEBRAND, 2010).

\section{PREVENÇÃO}

A prevenção de novos casos deverá ter como estratégia a informação para a população geral e, especialmente, para as populações mais vulneráveis (prostitutas, usuários de drogas intravenosas, etc.) sobre a doença e as formas de evitá-la (AVELLEIRA,2006).

É importante orientar o paciente, tentar mostrar a necessidade de se comunicar com o parceiro e estimular o uso de preservativo nas relações sexuais. A circulação contínua e a circulação contínua da equipe de saúde fazem parte desse conjunto de medidas de prevenção e controle da sífilis. 


\section{ATUAÇÃO DO FARMACÊUTICO}

Atualmente, os farmacêuticos têm vários ramos de atividade, incluindo Sua relevância como profissional de saúde pode ser comprovada por diversos ângulos. Em resposta à sífilis, em termos de diagnóstico, Resolução no 514 de 25 de novembro de 2009, garante ao farmacêutico a obtenção de título de especialista em análises clínicas. A análise clínica, portanto, tem responsabilidade técnica perante o laboratório, análise clínica para garantir a confiabilidade dos relatórios laboratoriais e influência afeta diretamente a segurança e a qualidade dos resultados dos testes de diagnóstico sífilis. A droga de escolha para o tratamento da sífilis, Penicilina benzatina, distribuída gratuitamente pelo SUS, e vendido em farmácias. Portanto, a resolução do conselho Colegiada-RDC no 44, de 17 de agosto de 2009, permite farmacêutico A distribuição segura desse ingrediente terapêutico (Brasil, 2010).

\section{REFERÊNCIAS}

SARKISIAN, S.A.; BRILLHART, D.An Emergency Department Presentation of Secondary Syphilis.Military Medicine, Oxford, v. o, n.o, p.I-2, 2018.

AVELLEIRA, J.C.R.; BOTTINO, G. Sífilis: diagnóstico, tratamento e controle. Anais Brasileiros de Dermatologia. Rio de Janeiro, v.8I, n.2, p.113,114,115,116, 2006. Disponível em: < RevABDfinalV8IN2.qxd (scielo.br)> Acesso em: 23 de junho de 202I. BRASIL. Ministério da Saúde. Manual técnico. Assistência pré-natal e puerpério: atenção qualificada e humanizada. Brasília (DF): Ministério da Saúde; 2005 a.

BRASIL. Ministério da Saúde. Secretaria de Vigilância em Saúde. Programa Nacional de DST e Aids. Diretrizes para o Controle da Sífilis Congênita. Brasília: Ministério da Saúde; 2005 b.

DORADO, J.S., AREllANO, E.R., PICHARDO, A.R., EZCURRA, M.A.M. Infecciones por treponemas. Sífilis. Medicine. v.II, n. 5I, p. 2993-3002. Acessado em: 23 de junho de 202I 
BRASIL. MINISTÉRIO DA SAÚDE. Portaria no 542, de 24 de dezembro de 1986. Dispõe sobre a regulamentação da notificação compulsória da sífilis. Diário Oficial da União 1986.

MACÊDO, V.C., LIRA, P.I.C., FRIAS, P.G., ROMAGUERA, L.M.D., CAIRES, S.F.F., XIMENES, R.A.A. Risk factors for syphilis in women: case-control study. Rev Saúde Pública. 51:78 2017

RODRIGUES. C.S., GUIMARÃES, M.D.C., Grupo Nacional de Estudo sobre Sífilis Congênita. Positividade para sífilis em puérperas: ainda um desafio para o Brasil. Rev Panam Salud Publica. 16(3):168-75, 2004

MILANEZ, H.; AMARAL, E. Por que ainda não conseguimos controlar o problema da sífilis em gestantes e recém-nascidos? Revista Brasileira de Ginecologia e Obstetrícia, Campinas, v.30, n.7, p.325-7, 2008.

KUZNIK, A., MUHUMUZA, C., KOMAKECH, H., MARQUES, E.M.R., LAMORDE, M. Antenatal syphilis screening using point-of-care testing in low- and middle-income countries in Asia and Latin America: a cost-effectiveness analysis. PLoSOne. Io(5):eo127379, 2015

SARACENI, V. Sífilis congênita. In: Passos MRL. Dessetologia. 5a ed. Rio de Janeiro: Cultura Médica; 2005. p. 215-24.

LAFETÁ , K. R. G. Sífilis materna e congênita, subnotificação e difícil controle. Revista Brasileira de Epidemiologia [online]. 2016, v. I9, n., pp.71. Disponível em: https://doi.org/10.1590/1980-5497201600o10006 . https://doi.org/10.1590/198o549720160oorooo6. Acessado em: 23 Junho 2021.

HESTON, S.; ARNOLD, S.Syphilis in Children.Infectious Disease Clinics of North America, Memphis, v.32, n.I, p.129-I44, Acessado em: 23 de junho de 202I

HERNANDES, CRISTIANE. Sífilis congênita: uma revisão da literatura, 2013, Santa Cruz do Sul, pg 02 \03, artigo, Universidade de Santa Cruz do Sul (unisc). Disponível 
em: <or6_reci_o6_artigo_de_revisao_oı.indd (researchgate.net)〉. Acessado em: 28 de junho de 2021

ERRANTE, P.R. Sífilis Congênita e Sífilis na Gestação, Revisão de Literatura. Revista UNILUS Ensino e Pesquisa v. 13, n. 31, p. 120-126, 2016. Acessado em: I2 de julho de 202I

TAMAY DE DIOS, L.; IBARRA, C. \& VELASQUILLO, C. Fundamentos de la reacción en cadena de la polimerasa (PCR) y de la PCR en tiempo real. Investigación en discapacidad. v.2, 70-78, 2013. Acessado em: 12 de julho de 2021

GUNSBURG, R.; SANTOS, A. M. N. Critérios diagnósticos e Tratamento da Sífilis Congênita: História. 2010. Disponível em: 〈http://www.sbp.com.br/fileadmin/user_upload/2015/o2/tratamento_sifilis.pdf〉 . Acessado em: I2 de julho de 2021.

MAHONEY, J.F., ARNOLD, R.C., HARRIS, A.D. Penicillin Treatment of Early Syphilis: a preliminary report. American Journal of Public Health and the Nation's Health. 33(12): 1387-91, 1943

SILVA, V. S. T. da.Os (Des) caminhos da Sífilis Congênita no Município de Botucatu/ São Paulo. 20I6. Io8 f. Dissertação (Mestrado) - Curso de Enfermagem, Universidade Estadual Paulista "Júlio de Mesquita Filho", Botucatu, 2016.

Damasceno, Alessandra, B.A, Sífilis na gravidez: Syphilis in pregnancy, Sífilis en el embarazo, v.13, n. 3, jul/set 2014, Rio de Janeiro. Acessado em: 27 de julho de 2021.

MORALES-MÚNERA, C.E.; FUENTES-FINKELSTEIN, P.A.; MAYANS, M. Vall. FR - Sífilis: actualizaciónenel manejo diagnóstico y terapéutico. ActasDermosifiliográficas, [s.1.], v. Io6, n. I, p.68-69, jan. 2014. Elsevier BV. http://dx.doi.org/ro.ıo16/j.ad.2014.06.007. 
SAMALVIDES-CUBA, F., BANDA-FLORES, C. L. Sífilis enlagestación. Rev Per Ginecol Obstet. 56:202-208, 2010

SOROA R.M, PUENTE R.Z, SOLERA O.C., COOB R.T. Manejo de la Sífilis em Atención Primária. FMC. 24(I):5-1I, 2017

MINISTÉRIO DA SAÚDE. Secretaria de Vigilância em Saúde. Programa Nacional de DST e Aids. Plano Operacional para Redução da Transmissão Vertical do HIV e da Sífilis. 2007.

MINISTÉRIO DA SAÚDE. Manual de Controle das Doenças Sexualmente Transmissíveis. $4^{\underline{a}}$ ed. Brasília, 2006 $\underline{a}$

HILDEBRAND, V.L.P.C. Sífilis congênita: fatores associados ao tratamento das gestantes e seus parceiros [dissertação]. Rio de Janeiro: Escola Nacional de Saúde Pública Sérgio Arouca: Escola Nacional de Saúde Pública Sérgio Arouca; 2010.

FIGUEIREDO, M.S.N., CAVALCANTE, E.G.R., OLIVEIRA, C.J., MONTEIRO, M.F.V., QUIRINO, G.S., OLIVEIRA, D.R. Percepção de enfermeiros sobre a adesão ao tratamento dos parceiros de gestantes com sífilis. Rev Rene. 16(3):345-54, 2015

GUIMARÃES, C.C; CARdOSO, C.Q.E.; OLIVEIRA, N.M; TEIXEIRA, O.; BARBOSA, T.; LOOSE, J.T.T. Sífilis em gestantes: prevenção e tratamento. Revista Enfermagem e Saúde Coletiva, São Paulo, v.2, n.3, p.71- 86, 2017. 